\title{
ESTUDOS SOBRE BLOGS NA CIÊNCIA DA INFORMAÇÃO'
}

\author{
STUDIES ON BLOGS IN INFORMATION SCIENCE
}

\author{
Jéssica Patrícia Silva de Sál
}

Recebido em: 09-03-2019

Aceito em: 20-04-2019

\begin{abstract}
Resumo
O presente artigo objetivou realizar um levantamento bibliográfico de estudos sobre blogs no campo da Ciência da Informação, com o intuito de investigar como os blogs são compreendidos como objetos de estudo nessa área do conhecimento. Como resultados, foram encontrados 37 trabalhos sobre blogs relacionados ao campo da Ciência da Informação, dos quais 26 são artigos de periódicos científicos, sete são dissertações de Mestrado e quatro são trabalhos apresentados em eventos científicos. Por meio da análise desses documentos foi possível elencar seis categorias, que auxiliam na compreensão de como os blogs são abordados nesses trabalhos, sendo elas: blogs como fontes de informação, blogs relacionados à Biblioteconomia, blogs como espaços sociais de representação, estudos da blogosfera, tratamento da informação em blogs e estudos sobre blogs literários. Ao final da pesquisa, verifica-se que os blogs já se constituem como objetos de pesquisa no campo da Ciência da Informação, destacando-se a diversidade de perspectivas por meio das quais os blogs são compreendidos.
\end{abstract}

Palavras-chave: Blogs. Levantamentos. Ciência da Informação.

\begin{abstract}
This article aims to carry out a bibliographic survey of studies on blogs in the field of Information Science, in order to investigate how blogs are understood as objects of study in this area of knowledge. As results, 37 papers on blogs related to the field of Information Science were found, of which 26 are articles from scientific journals, seven are Master's dissertations and four are papers presented at scientific events. Through the analysis of these documents it was possible to list six categories, which help in the understanding of how blogs are approached in these works: blogs as sources of information, blogs related to librarianship, blogs as social spaces of representation, blogosphere studies, treatment of information in blogs and studies on literary blogs. At the end of the research, it is verified that blogs are already constituted as objects of research in the field of Information Science, highlighting the diversity of perspectives through which blogs are understood.
\end{abstract}

Keywords: Blogs. Survey. Information Science.

\section{INTRODUÇÃO}

De modo geral, um blog se configura como um espaço virtual utilizado para publicação de informação escrita dos mais diversos gêneros. Conforme Pereira (2008), as principais características de um blog são a atualização constante e o formato de diários com textos, notícias e opiniões individualizadas com estilo informal e subjetivo. Outra importante característica de um blog é sua interatividade, que se dá por meio dos comentários possíveis de serem feitos nas

1 O presente artigo é oriundo de resultados da dissertação intitulada Ler e compartilhar na web: práticas informacionais de blogueiros literários, defendida em dezembro de 2018 junto ao Programa de Pós-graduação em Ciência da Informação da Universidade Federal de Minas Gerais (UFMG).

${ }^{1}$ Doutoranda em Ciência da Informação - UFMG - e-mail: j.jessicadesa@gmail.com 
postagens. Assim, um blog permite a comunicação entre os escritores de blogs, denominados blogueiros, e seus leitores.

A proposição de um estudo de blogs no âmbito da Ciência da Informação (CI) relacionase ao fato de que essa área configura-se como uma ciência social aplicada, possuindo um "objeto teórico que se constitui pela articulação de objetos empíricos, como pessoas, processos, instrumentos e produtos, cuja orientação é essencialmente pragmática" (ORTEGA, 2013, p. 2).

Nesse sentido, o presente artigo intenciona fazer um levantamento de estudos sobre blogs no campo da Ciência da Informação, objetivando compreender como o blog é analisado enquanto objeto de estudo nessa área do conhecimento.

\section{CONTEXTUALIZAÇÃO TEÓRICA}

A respeito do termo blog, não existe um consenso sobre sua utilização na forma escrita. $\mathrm{Na}$ literatura pesquisada, foram encontradas as terminologias: weblog, blog e também a utilização das terminologias weblog e blog em conjunto, como sinônimos. Foram encontrados dois artigos com o termo blogue (ALVIM, 2007; SOUSA et al., 2007), fator que pode estar relacionado à publicação dos mesmos ter sido em Portugal. É perceptível que estudos mais antigos utilizam o termo weblog e os mais recentes trabalham com a nomenclatura blog.

A grafia blogue é a versão oficialmente aportuguesada do termo, presente no dicionário Priberam e nos Vocabulários Oficiais da Academia Brasileira de letras (VOLP). Entretanto, a versão da língua portuguesa não é comumente utilizada pelos pesquisadores da Ciência da Informação no Brasil, que optam por weblog ou blog.

Os blogs são páginas que se diferenciam de outras páginas da web como, por exemplo, os websites. A maior divergência é na maneira como as informações são apresentadas na web. Os sites são o modelo tradicional de formatação de conteúdo na internet. Entretanto, a internet 2.0 permite que os internautas possam contar com espaços virtuais em que os conteúdos sejam geridos de forma colaborativa, com a inclusão de comentários de outros leitores; esses espaços são os blogs que integram a blogosfera ${ }^{2}$. Dessa forma, a web não é mais constituída de uma coleção de websites de consulta de informação, podendo se apresentar como uma plataforma inteligente na qual seus utilizadores finais podem, simultaneamente, ser usuários e produtores de informação (BOSLER; CALDEIRA; VENTURELI, 2011).

Quanto ao conceito de blog, Amaral, Recuero e Montardo (2009) concluem que os blogs podem ser definidos de maneira estrutural, funcional ou como artefatos culturais. A definição estrutural perpassa pela ideia de que um blog é uma ferramenta de publicação em um formato muito particular. Nessa concepção, a definição mais comum é apontar um blog como textos organizados em ordem cronológica reversa, datados e atualizados com frequência. $\mathrm{O}$ critério da frequência de publicação também é apontado como essencial. Entretanto, nem todos os autores consideram a presença da ferramenta de comentários como essencial. Compreender um blog a partir de sua definição estrutural é apreendê-lo enquanto formato, que permite usos e apropriações diversas.

$\mathrm{Na}$ linha da definição de blog como estrutura, alguns autores descrevem o blog em relação aos componentes presentes na página. "Um blogue é acima de tudo um sítio web onde são colocadas mensagens (habitualmente designadas por posts), por ordem cronológica invertida, sobre um ou vários temas" (SOUSA et al., 2007, p. 89). Uma definição semelhante é apresentada por Silva (2003) que conceitua o blog como um website extremamente flexibilizado, com posts organizados em ordem cronológica reversa e com interface de edição simplificada, que não exige a compreensão de qualquer tipo de código HTML (do inglês, Hypertext Markup Language). Outro aspecto ressaltado é a simplicidade de criação do blog,

\footnotetext{
${ }^{2}$ A comunidade formada por blogs e blogueiros.
} 
"um dos elementos que diferencia o weblog de outros sites diz respeito à facilidade com que este tipo de página pode ser construído [...]" (SILVA, 2008, p.4).

Já na concepção funcional, o blog é entendido na sua função primária como meio de comunicação. O blog é, portanto, mais do que uma ferramenta de publicação caraterizada por seu formato, sendo uma ferramenta de comunicação. A percepção dos blogs como constituintes de redes sociais e espaços de sociabilidade também pertencem à concepção funcional, pois ressaltam sua função comunicativa e os elementos que dela decorrem (AMARAL; RECUERO; MONTARDO, 2009).

A visão funcional de blog é identificada por alguns autores que ressaltam a questão da interação entre os indivíduos. Almeida (2008) considera a interatividade como característica dos blogs, descrevendo a relação entre os leitores e blogueiros, que ocorrem mediante o uso do e-mail contido no blog ou por meio dos comentários. Para Araújo e Vieira (2012), os blogs são produtos do ciberespaço, que reafirmam a comunicação interativa e a colaboração. Já Matos (2009) afirma que a interatividade é a condição de existir dos blogs enquanto ambientes virtuais.

A definição de blogs como artefatos culturais é advinda de um olhar antropológico e etnográfico. Vistos como artefatos culturais, os blogs são apropriados pelos sujeitos e constituídos por meio de marcações e motivações. Nessa visão, blogs são lugares de marcações culturais de determinados grupos e populações no ciberespaço, sendo possível, ao acessá-los, recuperar seus traços culturais (AMARAL; RECUERO; MONTARDO, 2009).

De acordo com Shah (2005 citado por AMARAL; RECUERO; MONTARDO, 2009), um artefato cultural pode ser definido como um repositório vivo de significados compartilhados que são produzidos por uma comunidade de ideias. $\mathrm{O}$ autor estudou os usos e apropriações dos blogs de pornografia pelas mulheres indianas e constatou que as motivações dos blogueiros podem revelar muito da própria significação da ferramenta. Ele argumenta que os blogs, enquanto artefatos culturais, podem revelar diferentes ideias do porquê que as pessoas blogam, pois a legitimação do blog se dá pelas práticas vividas pelas pessoas que os criaram.

O surgimento e popularização dos blogs vão ao encontro de uma demanda social de criar um espaço próprio onde se possa opinar, comentar, compartilhar fatos, notícias e até escrever sobre si mesmo. Em suas diferentes configurações, os blogs exercem o mesmo papel: tornar o blogueiro um protagonista. É o blogueiro quem está compartilhando conteúdo, quem avalia o que é importante, o que deve ser acessado, expressa suas opiniões, promove reflexões, exprime o que pensa. O blog é uma parte do blogueiro, em outras palavras, é como se o blogueiro abrisse seu mundo pessoal para os visitantes, no caso, os leitores.

No senso comum, ao se abordar a temática dos blogs, geralmente, é feita uma associação imediata com os diários pessoais. Mas, os blogs possuem outros formatos que vão além desse.

Sob os mais diferentes usos, o blog faz às vezes da agenda, do jornal, da página literária, do álbum de recordação, do caderno de anotar a vida ou diário pessoal, dentre outras infinitas finalidades, uma expressão inteiramente original que prevê a possibilidade de vários sujeitos empregarem a primeira pessoa em uma situação de diálogo e socialização da comunicação (CARNEIRO, 2011, p. 80).

Recuero (2003), ao realizar uma investigação e analisar diferentes blogs, identificou três categorias de blogs, sendo elas:

- Diários eletrônicos: são blogs atualizados com pensamentos, fatos e ocorrências da vida pessoal e do cotidiano do sujeito. A intenção desses blogs não é ser informativo ou publicar notícias, mas simplesmente servir como um canal de expressão do blogueiro.

- Publicações eletrônicas: são blogs que se destinam principalmente à disseminação de informação. Trazem notícias, dicas e comentários sobre um determinado assunto, como se 
fossem revistas eletrônicas. Comentários pessoais são evitados, embora tenham algumas ocorrências.

- Publicações mistas: são blogs que misturam posts pessoais sobre a vida do blogueiro e posts informativos, com notícias, dicas e comentários conforme o gosto pessoal.

Outra classificação é proposta por Silva (2003), que propõe duas categorias, sendo: Weblogs Temáticos, concebidos com base em um tema específico ou numa área de interesse comum, pode-se incluir blogs com propósitos educacionais, jornalísticos etc.; e Weblogs Livres, contendo publicações que não se atém a um único tema, com características próprias de uma página pessoal e formas de anotações livres, podendo incluir criação literária, comentários sobre o que se passa na "cabeça" do autor, críticas, fofocas, atualização de notícias, diários, entre outros.

Uma categorização semelhante é apresenta por Benedito (2003 citada por SOUSA et $a l .$, 2007) ao considerar que, no processo de evolução dos blogs, é possível identificar dois tipos: o blog-agenda, contendo pensamentos, ideias, comentários de livros lidos etc.; e o blogmural, que se apresenta como um "jornal de parede", composto por notícias, artigos de opinião e até imagens de acontecimentos, em primeira-mão, sem compromisso nem censura.

Vega e Rojo (2003) também criaram categorias de identificação dos blogs, classificando-os em:

- Pessoais: aqueles que refletem as impressões de uma pessoa sobre um tema ou sobre aspectos variados, muito abundantes na internet e pouco interessantes do ponto de vista informativo;

- Corporativos: advindos de determinadas instituições com o intuito de servir de boletim de comunicação e informação entre os membros da organização, transmitindo notícias e oferecendo recursos com foco nos procedimentos e políticas internas;

- Temáticos: páginas dedicadas a uma disciplina ou assunto, com um administrador e colaboradores, formadores de opinião.

Já Granado e Barbosa (2004 citados por SILVA, 2008) dividem os blogs em três tipos: Diários, descrições diárias de acontecimentos e eventos que preenchem a existência do autor; Analíticos, compostos por pequenos ensaios sobre temas ligados à atualidade ou assuntos em que o autor seja especializado; Informativos, originados por material retirado de outras páginas.

É possível reconhecer semelhanças nas categorizações propostas pelos diversos autores citados, conforme apresentado no Quadro 1.

Quadro 1 - Categorias de Blogs

\begin{tabular}{ll|ll}
\hline \multicolumn{2}{c}{ Diário Pessoal } & \multicolumn{2}{c}{ Conteúdo Temático } \\
\hline Diário Eletrônico & Recuero (2003) & Publicações & Recuero (2003) \\
Weblogs Livres & Silva (2003) & Eletrônicas & Silva (2003) \\
Blog-agenda & Benedito (2003) & Weblogs & Benedito (2003) \\
Pessoais & Vega e Rojo (2003) & Temáticos & Vega e Rojo (2003) \\
Diários & Granado e Barbosa (2004) & Blog-mural & Granado e Barbosa (2004) \\
& & Temáticos & \\
& & Analíticos & \\
& & & \\
\end{tabular}

Fonte: Elaborado pela autora, 2019. 
O blog como diário pessoal é encontrado nas categorias: Diário Eletrônico (RECUERO, 2003), Weblogs Livres (SILVA, 2003), Blog-agenda (BENEDITO, 2003), Pessoais (VEGA; ROJO, 2003) e Diários (GRANADO; BARBOSA, 2004). Já o blog como uma página com conteúdo temático é categorizado em: Publicações eletrônicas (RECUERO, 2003), Weblogs temáticos (SILVA, 2003), Blog-mural (BENEDITO, 2003), Temáticos (VEGA; ROJO, 2003) e Analíticos (GRANADO; BARBOSA, 2004).

Para Recuero (2003, p. 5), é importante ressaltar a existência de diversas formas de blogs, evitando a generalização do blog como ferramenta específica de construção de diários, uma vez que os "blogs têm sido utilizados das mais diversas formas, todas relacionadas à publicação de ideias, algumas pessoais (diários) outras informacionais (publicações)".

Além de categorizar os blogs quanto ao conteúdo, Silva (2003) classifica-os quanto à produção: Weblog individual, cujo criador do blog é o único capaz de postar conteúdos, estando a página sob a responsabilidade de uma única pessoa, o que até certo grau reflete a personalidade do indivíduo que o mantém; Weblog coletivo, no qual mais de uma pessoa pode postar; nesse caso, o criador/administrador do blog tem a opção de controlar quem pode escrever, permitindo que múltiplos autores participem da manutenção do mesmo site, motivados por interesses semelhantes.

É interessante observar que as categorizações servem como elementos norteadores para o estudo dos blogs, mas as classificações não devem ser entendidas como restritas e rígidas; afinal, um blog pode pertencer a mais de uma categoria, sendo um híbrido de dois formatos. Além disso, no decorrer da evolução dos blogs, podem surgir novos elementos que determinem outras categorias.

\section{OBJETIVOS}

O objetivo desta pesquisa foi realizar um levantamento bibliográfico de trabalhos no campo da Ciência da Informação que possuem blogs como objetos de estudo. Tal levantamento pretendia constatar a existência do blog como temática estudada no campo da CI e a análise de quais perspectivas estão sendo abordadas nesses estudos. É importante destacar que esse levantamento bibliográfico não pretendeu apresentar-se como uma pesquisa bibliométrica.

\section{METODOLOGIA}

Conforme os dados do levantamento, realizado em maio de 2018, os blogs já apresentam-se como objetos de estudo na CI. Foram realizadas buscas com os termos "blog", "blogs", "blogs literários" e "blogosfera" associados ao termo "Ciência da Informação" nas bases de dados: Scientific Electronic Library Online (SciELO), Portal de Periódicos da Coordenação de Aperfeiçoamento de Pessoal de Nível Superior (CAPES), Biblioteca Digital Brasileira de Teses e Dissertações (BDTD) e Base PERI da Escola de Ciência da Informação da UFMG. Além das bases, foi também utilizado o motor de busca Google Acadêmico. No total foram encontrados 37 trabalhos sobre blogs no campo da CI.

Ressalta-se que a simples menção dos termos relacionados à temática dos blogs não foi considerada nesse levantamento, sendo compilados somente os trabalhos que possuíam os termos presentes no título, resumo ou palavras-chave, ou seja, os que realmente tratavam os blogs como objeto de estudo.

\section{RESULTADOS}

Dos 37 trabalhos recuperados no levantamento, 26 são artigos de periódicos científicos, sete são dissertações e quatro são trabalhos apresentados em eventos científicos da área. Por meio da análise desses documentos foi possível elencar seis categorias, que auxiliam na compreensão de como os blogs são abordados nos trabalhos. Quatro das categorias formadas compreendem diferentes campos de estudo vinculados à CI como: fontes de informação, 
Biblioteconomia, tratamento da informação e responsabilidade social. As outras duas categorias compreendem os estudos da blogosfera e os estudos sobre blogs literários.

Foi elaborado um gráfico que apresenta o número de trabalhos encontrados em cada uma das seis categorias, conforme apresentado no Gráfico 1.

Gráfico 1 - Número de trabalhos por categoria

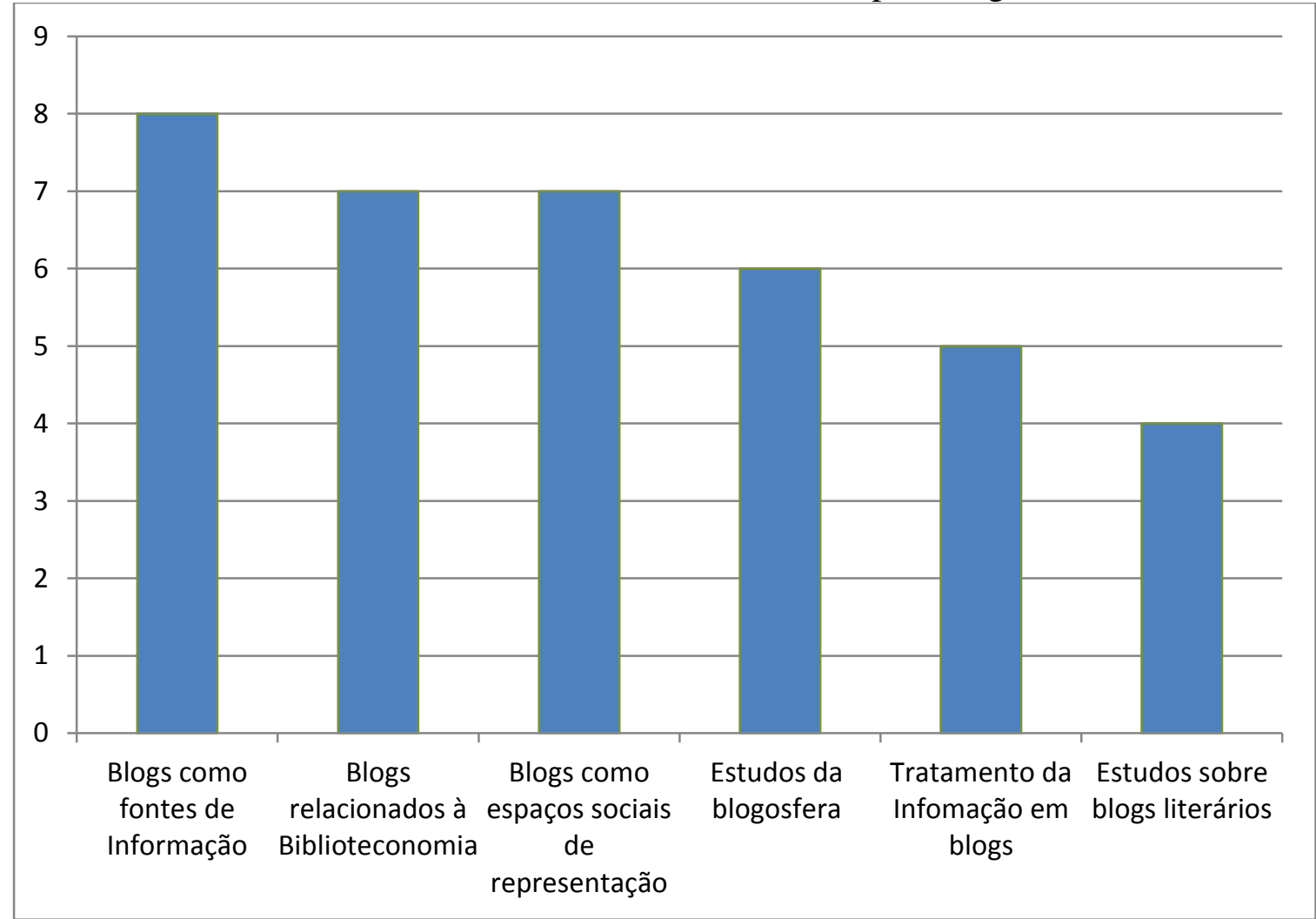

Fonte: Elaborado pela autora, 2019.

\subsection{BLOGS COMO FONTES DE INFORMAÇÃO}

Dentre as pesquisas encontradas, oito trabalhos consideram os blogs na perspectiva de fontes de informação, como disseminadores de informações na web. Dessa forma, a tipologia de blogs como fontes de informação foi a que apareceu com maior frequência.

Em sua dissertação, Silva (2006) analisa os blogs como fontes de informação para jornalistas, e em um artigo propõe o blog como objeto de estudo na CI, pelo uso da ferramenta na criação, distribuição, comunicação, armazenamento e recuperação da informação (SILVA, 2008). Sousa et al. (2007) apontam os blogs como passíveis de serem inseridos nos sistemas de informação, na perspectiva da gestão da informação. Eiras (2007) propõe a criação de blogs por parte dos profissionais da documentação e informação, como forma de divulgação das unidades de informação e também como ferramenta para partilha, troca de experiências entre os pares.

Silva et al. (2011) apontam a importância do uso do blog como fonte de informação e também como ferramenta de trabalho do bibliotecário. A pesquisa de Pinheiro (2014) também aborda os blogs como fontes de informação relacionadas à Biblioteconomia, pois objetivou investigar o uso de blogs e listas de discussão sobre Biblioteconomia e Ciência da Informação no Brasil.

O blog "De Olho na CI" foi objeto de estudo de vários trabalhos, uma vez que é um projeto vinculado ao Departamento de Ciência da Informação da Universidade Federal da Paraíba (UFPB). Freire, Lima e Costa Júnior (2012) compartilham a experiência com a edição 
e publicação do blog, que tem como público-alvo pesquisadores e profissionais da informação, objetivando divulgar conteúdo referente à Ciência da Informação, Biblioteconomia, Arquivologia e Museologia. Por sua vez, Freire, Santos e Nascimento (2014) apresentam um estudo sobre o blog "De Olho na CI" analisando a produção e transferência de informação, na perspectiva da gestão da informação.

Percebe-se que o ponto central dessas pesquisas é a compreensão do blog como uma fonte de informação, identificando o potencial da plataforma blog na publicação de conteúdo atualizado e relevante, principalmente para profissionais. Dessa forma, essas pesquisas evidenciam a possível atuação dos blogs na disseminação da informação na web, propiciando seu acesso para diversos usuários.

\subsection{BLOGS RELACIONADOS À BIBLIOTECONOMIA}

A análise de sete trabalhos revelou que seus objetivos estão especificamente relacionados ao estudo do vínculo entre os blogs e a Biblioteconomia.

Alvim (2007) apresenta os blogs como ferramentas que as bibliotecas podem utilizar em duas perspectivas: como fonte de informação e como forma de promover os seus serviços, proporcionando canais de comunicação com os usuários. O blog e a sua relação com a divulgação de informação e promoção do profissional bibliotecário estão presente no artigo de Araújo (2010) e também no artigo de Corrêa, Zamban e Oliveira (2013), que trata, especificamente, do blog "Bibliotecários sem Fronteiras".

O uso do blog como ferramenta da biblioteca 2.0 é ressaltado por Vieira e Baptista (2011). Os blogs usados em bibliotecas também são tema do artigo de Ramos (2016), que apresenta avaliação do blog de uma biblioteca universitária, verificando sua qualidade e usabilidade. A autora enfatiza a inegável importância da utilização dos blogs por bibliotecas, não só pelo caráter informativo, mas também pela maior aproximação da instituição com seus usuários.

A divulgação de bibliotecas e espaços culturais por meio dos blogs é temática discutida por Magalhães (2015), que apresenta o blog "Caçadores de Bibliotecas" como um veículo informacional, que publica conteúdos relacionados a espaços culturais diversos e diferentes tipos de biblioteca, ressaltando a importância da divulgação dos espaços de atuação do profissional da informação.

O blog também foi abordado como plataforma possível de ser utilizada em cursos de Graduação em Biblioteconomia. A partir de um relato de experiência, Sampaio (2011) descreve a utilização do blog como portfólio eletrônico de uma disciplina.

Conclui-se que o foco dos trabalhos citados é defender o uso de blogs como formas de divulgação de bibliotecas, tornando-as mais conhecidas, de forma a explicitar os serviços oferecidos e atrair novos usuários. Além disso, a promoção do trabalho do bibliotecário por meio dos blogs é uma forma de valorização desse profissional que, em muitas circunstâncias e contextos, não possui o devido reconhecimento.

\subsection{BLOGS COMO ESPAÇOS SOCIAIS DE REPRESENTAÇÃO}

Foram encontrados sete trabalhos que relacionavam os blogs, no âmbito da CI, à representação social e cultural de grupos e comunidades.

Em pesquisa de Mestrado, Farias (2011) objetiva promover a inclusão da comunidade Santa Clara na sociedade da informação mediante registro e publicação da memória social dessa comunidade localizada no estado da Paraíba. Assim, a autora identifica o regime de informação e as fontes de informação na comunidade, criando um blog para registrar e disseminar os seus conhecimentos, compreendendo-o como uma ferramenta de inclusão social. No mesmo ano, a autora publicou um artigo em coautoria com a orientadora de Mestrado, no qual descrevem a experiência da criação do blog na comunidade Santa Clara como forma de preservar a memória 
social e o saber popular. O blog foi visto como uma ferramenta de empoderamento da comunidade, valorização da identidade cultural dos moradores e também como instrumento de comunicação (FARIAS, FREIRE, 2011). No mesmo sentido, Silva (2014) também trabalha na perspectiva da responsabilidade social da Ciência da Informação, uma vez que sua dissertação objetivou o planejamento e a construção de um blog para democratização de informações de interesse para pessoas com deficiência no estado da Paraíba.

Silva, Silva Júnior e Aquino (2013) investigam como o Movimento Negro do Estado da Paraíba se apropria dos gêneros digitais, sendo um deles o blog, utilizando-os para disseminar a informação étnico-racial. Silva Júnior (2014) apresenta em sua dissertação o uso da netnografia para o estudo dos blogueiros. Seu objetivo foi averiguar a construção da identidade negra a partir de informações disseminadas em blogs de funk. Sua pesquisa apresenta um forte viés cultural e trabalha a interpretação da informação e sua apropriação no ponto de vista dos sujeitos.

Os blogs como espaços de livre expressão são discutidos por Silveira (2011), que defende o blog como substituto da imprensa alternativa da época do regime militar brasileiro e dos jornais de cunho político do final do século XIX. Sendo assim, a autora alerta para a necessidade de preservação dos blogs como forma de manter a memória nacional registrada da atualidade. É apresentado o conceito de arquivamento da web como forma de preservação digital dos blogs de manifestações políticas e movimentos sociais. Nessa perspectiva, Targino (2013) analisa blogs cubanos como espaço de luta para (re)conquista da cidadania, em especial o blog "Generación $Y$ ", que se apresenta como espaço genuíno de crítica à realidade do povo cubano, sendo também uma alternativa à reivindicação de direitos, promovendo o exercício da liberdade de expressão e o intercâmbio de informações.

Compreende-se que o ponto comum dessas pesquisas é abordar o blog como um meio para promover uma representação social de certos grupos e comunidades, que muitas vezes são desprovidos de espaço para expressão ou são socialmente oprimidos. O blog, como uma ferramenta de fácil criação e uso, possibilita o empoderamento desses grupos, que podem comunicar-se livremente por meio da web. Os blogs, nesses casos, são concebidos como artefatos culturais, revelando traços indentitários e culturais de seus autores.

\subsection{ESTUDOS DA BLOGOSFERA}

Foram identificadas seis pesquisas que realizam estudos sobre blogs, possuindo enfoque na blogosfera e nos blogueiros.

Caregnato e Sousa (2010) realizam um estudo exploratório das redes formadas por blogs científicos brasileiros, investigando formas de recuperação e as características estruturais desses blogs, com o objetivo de compreender seu papel no âmbito da comunicação da ciência. Em uma outra pesquisa, Sousa e Caregnato (2012) analisam o fluxo da comunicação científica a partir do uso de links nas postagens dos blogs de pesquisadores brasileiros.

Em uma pesquisa voltada para a interação possibilitada pelos blogs, Araújo e Vieira (2012) interpretam a blogosfera como uma rede social. A partir da análise das redes sociais, os autores verificam a blogosfera averiguando sua expressividade, o nível de interatividade entre os blogs e os laços estabelecidos. Em 2013, Araújo e Teixeira analisam a "biblioblogosfera" brasileira, realizando uma pesquisa exploratória com abordagem cibermétrica, objetivando mapear os blogs sobre Biblioteconomia no país e analisá-los quanto ao gênero, interatividade e abordagem temática. Por meio da análise de redes sociais, os autores verificaram a baixa interconectividade dos blogs.

Ao abordar os sujeitos atuantes na blogosfera, Biscalchin (2012) apresentou uma postura etnográfica em sua dissertação, na qual realizou um estudo de caso exploratório e descritivo sobre um blog de entretenimento. A autora objetivou compreender o papel dos blogs e a influência da blogosfera na troca de informações, abordando questões como a autoria, o uso 
de links e as questões de visibilidade que permeiam as relações mediadas pelas tecnologias da informação. O termo práticas informacionais foi utilizado esporadicamente no decorrer da pesquisa referindo-se à participação dos blogueiros na blogosfera. A etnografia virtual foi usada por Lima (2013) ao abordar a mídia "De Olho na CI" como objeto de sua dissertação. A partir da análise documental e da análise de redes sociais, a autora conclui que as mídias "De Olho na CI" formam redes sociais na internet.

Nos estudos sobre a blogosfera é evidenciada a formação de redes, nas quais os blogs encontram-se conectados. $\mathrm{O}$ foco desses trabalhados é compreender o fluxo de informação nas redes formadas na blogosfera, sendo a análise de redes sociais um dos métodos comumente utilizados.

\subsection{TRATAMENTO DA INFORMAÇÃO EM BLOGS}

Conteúdos relacionados às temáticas de organização e tratamento da informação em blogs foram identificados em cinco trabalhos.

Inafuko e Vidotti (2012) analisam os blogs de bibliotecas do ponto de vista da arquitetura da informação e da usabilidade, apresentando diretrizes para o desenvolvimento e avaliação desses blogs. Santana Júnior et al. (2017) realizam um experimento com uma ferramenta voltada para a recuperação de informação em $b \log s$, tendo como referência, o padrão de microformatos.

Abordando a temática da indexação, a pesquisa de Gaudêncio (2014), em nível de Mestrado, averiguou a representação da informação dos cibercordéis em blogs por meio de procedimentos semânticos centrais no processo de indexação. $\mathrm{O}$ autor direcionou sua pesquisa para a questão do tratamento da informação e como os blogs podem auxiliar a entender, representar, preservar e divulgar produções culturais. Também relacionado à indexação, o artigo de Javanovich e Tomaél (2014) analisa a utilização das terminologias "informação jurídica" e "jurisprudência" em blogs da área de Direito. Santos, Neves e Freire (2017) realizaram uma pesquisa quanti-qualitativa para analisar o uso das etiquetas no blog "De Olho na CI", organizando as temáticas abordadas em nove categorias. O estudo atenta para a necessidade de padronização dos usos das etiquetas para melhor representação dos conteúdos no blog.

Conclui-se que os estudos sobre o tratamento da informação em blogs evidenciam a necessidade de organizar a informação disponibilizada nesse meio, mediante o uso de técnicas como a indexação, de forma que ela possa ser facilmente recuperada posteriormente. $\mathrm{O}$ fato de existir uma preocupação com o tratamento da informação nos blogs está diretamente vinculado à compreensão de que eles são fontes de informação.

\subsection{ESTUDOS SOBRE BLOGS LITERÁRIOS}

Foram identificados quatro estudos sobre blogs literários na área da CI. Apesar de não utilizar o termo "blogs literários", Dodebei (2009) discorre sobre a memória, os livros, a leitura e sua relação com as novas tecnologias, como os blogs. De acordo com a autora, blogs e websites são depositários das narrativas na atualidade. Dodebei ressalta a característica hipertextual da leitura nos espaços virtuais e a interatividade entre autor e leitor.

Gomes e Carvalho (2017) analisam o universo feminino em blogs de literatura erótica. As autoras realizam uma pesquisa qualitativa com observação direta de cinco blogs voltados para esse tipo de literatura. Constatou-se que esses blogs são escritos por mulheres e têm um público majoritariamente feminino, que utiliza o espaço para compartilhar experiências de relacionamentos, divulgar e discutir a literatura erótica.

Na perspectiva dos blogs literários e sua relação com a promoção da leitura, MansoRodriguéz (2015) investiga o uso das ferramentas tecnológicas e como elas contribuem para o incentivo à leitura, citando o blog como ferramenta usada frequentemente na implementação 
de ações de incentivo à leitura, como por exemplo, clubes do livro. $\mathrm{O}$ autor também caracteriza os blogs como via de intercâmbio de informação entre os leitores. Em uma outra pesquisa, Araújo e Araújo (2015) pesquisam os blogs como ferramentas de mediação de leitura. Para esses autores, os blogs são vistos como comunidades formadas por blogueiros e leitores que, como admiradores de livros e leitura, utilizam das ferramentas da rede para mediarem a leitura entre si.

É perceptível nesses estudos o forte viés do blog como uma ferramenta de incentivo à leitura e promoção da literatura no ciberespaço. O blog é também compreendido como um espaço que possibilita a interação entre os leitores literários.

\section{CONSIDERAÇÕES SOBRE OS ESTUDOS DE BLOGS NA CIÊNCIA DA INFORMAÇÃO}

Ao final da análise das 37 pesquisas identificadas por meio do levantamento bibliográfico, verificou-se que os blogs já se constituem como objetos de pesquisa no campo da Ciência da Informação. Destaca-se a diversidade de perspectivas por meio das quais os blogs são compreendidos: fontes de informação, veículo de comunicação e divulgação, meio para valorização profissional, espaços de representação social, redes sociais e ferramentas de incentivo à leitura. Acredita-se que além dessas existam também muitas outras possibilidades para analisar esses espaços virtuais dentro do campo da CI.

É perceptível uma certa concentração de pesquisas sobre blogs na Universidade Federal da Paraíba, visto que das sete dissertações analisadas, cinco foram defendidas nessa instituição. As dissertações de Farias (2011), Lima (2013) e Silva (2014) foram orientadas pela Professora Isa Maria Freire. É percebida, também, a forte presença de Freire em quatro artigos.

Em relação à temporalidade, foram encontrados trabalhos mais antigos, elaborados na década de 2000, época do surgimento dos blogs no Brasil. No entanto, a maioria dos trabalhos concentra-se no início da década de 2010, período de grande crescimento do número de blogs. Foram também encontrados trabalhos atuais, dos anos de 2015, 2016 e 2017, que demonstram a permanência dos blogs no ciberespaço.

\section{REFERÊNCIAS}

ALMEIDA, Patrícia Pinheiro. Fontes de informação literária na internet: uma avaliação. 2008. 91 f. Dissertação (Mestrado em Literatura) - Centro de Comunicação e Expressão, Universidade Federal de Santa Catarina, Florianópolis, 2008. Disponível em: https://repositorio.ufsc.br/xmlui/handle/123456789/91389. Acesso em: 03 mar. 2019.

ALVIM, Luisa. Blogue e bibliotecas: construir redes na Web 2.0. Cadernos BAD, Lisboa, Portugal, n. 1, p. 38-74, jan./jun. 2007.

AMARAL, Adriana; RECUERO, Raquel; MONTARDO, Sandra. Blogs: mapeando um objeto. In: Blogs.com: estudos sobre blogs e comunicação. São Paulo: Momento Editorial, 2009. p. 27-54. Disponível em: http://www.raquelrecuero.com/imagens/blogs\%20boneco\%20copy.pdf. Acesso em: 03 mar. 2019.

ARAÚJO, Paula Carina. O blog na "era da informação" como ferramenta de compartilhamento de informação, conhecimento e para promoção profissional. Revista ACB: Biblioteconomia em Santa Catarina, Florianópolis, v. 15, n. 1, p. 201-213 jan./jun. 2010. Disponível em: https://revista.acbsc.org.br/racb/article/view/676. Acesso em: 03 mar. 2019. 
ARAÚJO, Rafaela Lima de; ARAÚJO, Ronaldo Ferreira de. Ler, compartilhar e interagir: blogs como ferramenta de mediação de leitura. Revista ACB: Biblioteconomia em Santa Catarina, Florianópolis, v. 20, n. 2, p. 240-260, maio/ago. 2015. Disponível em: https://revista.acbsc.org.br/racb/article/view/1042/pdf. Acesso em: 03 mar. 2019. ARAUJO, Ronaldo Ferreira de; TEIXEIRA, Josemar Coltt da Silva. Biblioteconomia conectada: uma análise da biblioblogosfera brasileira. Revista ACB: Biblioteconomia em Santa Catarina, Florianópolis, v. 18, n. 2, p. 949-978, jul./dez. 2013. Disponível em: https://revista.acbsc.org.br/racb/article/view/924/pdf. Acesso em: 03 mar. 2019.

ARAÚJO, Ronaldo Ferreira de; VIEIRA, Rosiene Marques. Blogosfera como rede social: análise da interatividade dos blogs de Alagoas. Revista Informe: Estudos em Biblioteconomia e Gestão da Informação, Recife, v. 1, n. 1, p. 65-77, 2012. Disponível em: https://periodicos.ufpe.br/revistas/INF/article/download/44/82. Acesso em: 03 mar. 2019.

BENEDITO, Joviana. Dicionário da internet e do telemóvel. Lisboa: Centro Atlântico, 2003. 359 p.

BISCALCHIN, Ana Carolina Silva. Blogs de entretenimento: um estudo exploratório da circulação e legitimação da informação na internet brasileira. 2012. 134 f. Dissertação (Mestrado em Ciência da Informação) - Escola de Comunicação e Artes, Universidade de São Paulo, São Paulo, 2012.

BOSSLER, Ana Paula; CALDEIRA, Pedro Zany; VENTURELLI, Diego. Sites e blogs: definição, conceitos e passo a passo. In: MOURA, Maria Aparecida (Org.). Cultura informacional e liderança comunitária: concepções e práticas. Belo Horizonte: UFMG, 2011. p. 99 -104. Disponível em: https://www.ufmg.br/proex/cpinfo/cultura/docs/15a_Sites_e_blogs_-_Ana_Pedro_Diego.pdf. Acesso em: 03 mar. 2019.

CAREGNATO, Sonia Elisa; SOUSA, Rodrigo Silva Caxias de. Blogs cientificos.br? um estudo exploratório. Informação \& Informação, Londrina, v. 15, p. 56-74, 2010. Disponível em: http://www.uel.br/revistas/uel/index.php/informacao/article/view/5996/6779. Acesso em: 03 mar. 2019.

CARNEIRO, Jéssica de Souza. Ler e escrever blogs literários: a narrativa hipertextual na configuração da webliteratura. 2011. 217 f. Dissertação (Mestrado em Estudos Literários) Instituto de Letras e Comunicação, Universidade Federal do Pará, Belém, 2011.

CORRÊA, Elisa Cristina Delfini; ZAMBAN, Débora; OLIVEIRA, Viviane Martins Arruda de. Blogs sobre Biblioteconomia e a ressignificação da profissão no Brasil: uma análise do blog Bibliotecários sem fronteiras. Revista ACB: Biblioteconomia em Santa Catarina, Florianópolis, v. 18, n. 1, p. 698-715, jan./jun., 2013. Disponível em: https://revista.acbsc.org.br/racb/article/view/876. Acesso em: 03 mar. 2019.

DODEBEI, Vera. Novos meios de memória: livros e leitura na época dos weblogs. Encontros Bibli: revista eletrônica de biblioteconomia e ciência da informação, Florianópolis, n. 1, p. 129-143, 2009. Disponível em: https://periodicos.ufsc.br/index.php/eb/article/view/15182924.2009v14nesp1p129/19839. Acesso em: 03 mar. 2019. 
EIRAS, Bruno Duarte. Blogs: mais que uma tecnologia, uma atitude. Cadernos BAD, Lisboa, Portugal, n.1, p.75-86, jan./jun. 2007. Disponível em:

https://www.bad.pt/publicacoes/index.php/cadernos/article/view/782. Acesso em: 03 mar. 2019.

FARIAS, Maria Giovanna Guedes. A inclusão da comunidade Santa Clara na sociedade da informação. 2011. 121 f. Dissertação (Mestrado em Ciência da Informação) - Centro de Ciências Sociais Aplicadas, Universidade Federal da Paraíba, João Pessoa, 2011.

FARIAS, Maria Giovanna Guedes; FREIRE, Isa Maria. Memória do cotidiano: registro da comunidade Santa Clara na web. Em Questão, v. 17, n. 2, p. 119-133, 2011. Disponível em: http://www.brapci.inf.br/v/a/11517. Acesso em: 03 mar. 2019.

FREIRE, Isa Maria; LIMA, Aline Poggi Lins de; COSTA JUNIOR, Maurício Pereira da. Mídias sociais na web: De olho na CI para capacitação acadêmica e profissional. Biblionline, João Pessoa, v. 8, p. 175-184, 2012. Disponível em:

http://periodicos.ufpb.br/ojs2/index.php/biblio/article/view/14202/8108. Acesso em: 03 mar. 2019.

FREIRE, Isa Maria; SANTOS, Raimundo Nonato Ribeiro dos; NASCIMENTO, Breno Oliveira Nóbrega do. Gestão da Informação no blog De olho na CI. Informação \& Informação, Londrina, v. 19, n. 1, p. 95 - 111, jan./abr. 2014. Disponível em: http://www.uel.br/revistas/uel/index.php/informacao/article/view/15689. Acesso em: 03 mar. 2019.

GAUDÊNCIO, Sale Mário. Representação da informação de cibercordéis em blogs: uma análise sob a luz da semântica discursiva. 2014. 232 f. Dissertação (Mestrado em Ciência da Informação) - Centro de Ciências Sociais Aplicadas, Universidade Federal da Paraíba, João Pessoa, 2014.

GRANADO, Antônio; BARBOSA, Elizabete. Weblogs: Diário de Bordo. Portugal: Porto Editora, 2004.

GOMES, Maitê Celly da Silva; CARVALHO, Luciana Moreira. Literatura erótica em blogs: análise do universo feminino nos blogs de literatura erótica. Revista Informação na Sociedade Contemporânea, Natal, v. 1, n. 3, jul./dez. 2017. Disponível em: https://periodicos.ufrn.br/informacao/article/view/12273. Acesso: 03 mar. 2019.

INAFUKO, Laura Akie Saito; VIDOTTI, Silvana Aparecida Borsetti Gregorio. Diretrizes para o desenvolvimento e a avaliação de blogs de biblioteca. Encontros Bibli: Revista Eletrônica de Biblioteconomia e Ciência da Informação, Florianópolis, v. 17, n. 35, p. 145166, 2012. Disponível em: https://periodicos.ufsc.br/index.php/eb/article/view/15182924.2012v17n35p145/23586. Acesso em: 03 mar. 2019.

JOVANOVICH, Eliane Maria da Silva; TOMAÉL, Maria Inês. A abordagem da informação jurídica e da jurisprudência em blogs: um estudo comparativo entre termos. Revista ACB: Biblioteconomia em Santa Catarina, Florianópolis, v. 19, n. 2, p. 151-162, jul./dez. 2014. Disponível em: https://revista.acbsc.org.br/racb/article/view/981. Acesso em: 03 mar. 2019. 
LIMA, Aline Poggi Lins de. Mídias sociais na web: uma análise da mídia De olho na CI na perspectiva da disseminação da informação. 2013. 121 f. Dissertação (Mestrado em Ciência da Informação) - Centro de Ciências Sociais Aplicadas, Universidade Federal da Paraíba, João Pessoa, 2013.

MAGALHÃES, Soraia Pereira. O Blog Caçadores de Bibliotecas e a construção de conteúdos. Revista Brasileira de Biblioteconomia e Documentação, São Paulo, v. 11, p. 333-348, jul. 2015. Disponível em: https://rbbd.febab.org.br/rbbd/article/view/515/435. Acesso em: 03 mar. 2019.

MANSO-RODRÍGUEZ, Ramón-Alberto. Leer, comentar, compartir: El fomento de la lectura y las tecnologías sociales. TransInformação, Campinas, v. 27, n. 1, p. 9-19, jan./abr. 2015. Disponível em: http://www.scielo.br/pdf/tinf/v27n1/0103-3786-tinf-27-01-00009.pdf. Acesso em: 03 mar. 2019.

MATOS, Adriana Dória. Escritores de blogs: a web como espaço de criação e discussão sobre literatura. Hipertextus, n. 3, jun. 2009. Disponível em: http://hipertextus.net/volume3/Adriana-Doria-MATOS.pdf. Acesso em: 03 mar. 2019.

ORTEGA, Cristina Dotta. Ciência da Informação: do objetivo ao objeto. In: RENDÓN ROJAS, Miguel Ángel (Org.). El objeto de estudio de labibliotecología/documentación/ciencia de la información: propuestas, discusión, análisis y elementos comunes. México: UNAM/Instituto de InvestigacionesBibliotecológicas y de la Información, 2013. p. 151-177.

PEREIRA, Maria Leopoldina. Blogs literários como gênero do discurso: contribuição para a formação do leitor/autor. In: SIMPÓSIO HIPERTEXTO E TECNOLOGIAS NA EDUCAÇÃO, 2., 2008, Recife. Anais [...] Recife: Universidade Federal de Pernambuco, 2008. Disponível em: https://www.ufpe.br/nehte/simposio2008/anais/Maria-LeopoldinaPereira.pdf. Acesso em: 03 mar. 2019.

PINHEIRO, Mariza Inês da Silva. Estudo do uso das listas de discussão e dos blogs brasileiros em Biblioteconomia. Revista Brasileira de Biblioteconomia e Documentação, São Paulo, v. 10, n. 2, p. 174-188, jul./dez. 2014. Disponível em: https://rbbd.febab.org.br/rbbd/article/view/270/386. Acesso em: 03 mar. 2019.

RAMOS, Marília Cossich. Usabilidade do blog da Biblioteca Leopoldo Nachbin do Instituto de Matematica da UFRJ: estudo de caso. In: SEMINARIO NACIONAL DE BIBLIOTECAS UNIVERSITARIAS, 18, 2014, Belo Horizonte. Anais [...] Belo Horizonte: UFMG, 2016. Disponível em: https://www.bu.ufmg.br/snbu2014/wp-content/uploads/trabalhos/74-2077.pdf. Acesso em: 03 mar. 2019.

RECUERO, Raquel da Cunha. Weblogs, Webrings e comunidades virtuais. Revista 404notFound, v. 1, n. 31, 2003. Disponível em: http://www.raquelrecuero.com/artigos.html. Acesso em: 03 mar. 2019.

SAMPAIO, Débora Adriano. A experiência da utilização de blogs na disciplina Teoria e Prática da Leitura: construindo o portfólio eletrônico. Revista Digital de Biblioteconomia e Ciência da Informação, Campinas, v. 9, n. 1, p. 243-251, jul./dez. 2011. Disponível em: http://www.sbu.unicamp.br/seer/ojs/index.php/sbu_rci/index. Acesso em: 03 mar. 2019. 
SANTANA JÚNIOR, Célio Andrade et al. Uma ferramenta para recuperação de tags de blogs baseada em microformatos. Tendências da Pesquisa Brasileira em Ciência da Informação, v. 7, n. 2, p. 289-306, jul./dez. 2014. Disponível em:

http://inseer.ibict.br/ancib/index.php/tpbci/article/view/166/207. Acesso em: 03 mar. 2019.

SANTOS, Raimundo Nonato Ribeiro dos; NEVES, Dulce Amélia de Brito; FREIRE, Isa Maria. Organização da informação em blogs: análise do uso de etiquetas no blog de olho na CI. Ponto de Acesso, Salvador, v. 11, n. 1, p. 2-19, abr. 2017. Disponível em: https://portalseer.ufba.br/index.php/revistaici/article/view/21438/14662. Acesso em: 03 mar. 2019.

SHAH, N. PlayBlog: Pornography, performance and cyberspace. Cut-up.com Magazine, Holanda, v. 25, 2005.

SILVA, Eliane Ferreira da et al. Blogs: relevante ferramenta para o fazer bibliotecário. In: CONGRESSO BRASILEIRO DE BIBLIOTECONOMIA, DOCUMENTACÃO E CIÊNCIA DA INFORMACÃO, 24., 2011, Maceió. Anais [...] Maceió: Febab, 2011. Disponível em: http://www.febab.org.br/congressos/index.php/cbbd/xxiv/paper/view/246/530. Acesso em: 03 mar. 2019.

SILVA, Hellosman de Oliveira. Construção do sítio virtual para democratização da informação para pessoas com deficiência no Estado da Paraíba. 2014. 198 f. Dissertação (Mestrado em ciência da informação) - Centro de Ciências Sociais Aplicadas, Escola de Ciência da Informação. Universidade Federal da Paraíba, João Pessoa, 2014.

SILVA, Inara Souza da. Weblog como fonte de informação para jornalistas. 2006. $100 \mathrm{f}$. Dissertação (Mestrado em Ciência da Informação) - Faculdade de Economia, Administração, Contabilidade, Ciência da Informação e Documentação, Universidade de Brasília, Brasília, 2006.

SILVA, Inara Souza da. Weblog como objeto da Ciência da Informação. DataGramaZero, v. 9, n. 8, out. 2008. Disponível em: http://www.brapci.inf.br/index.php/article/download/7636. Acesso em: 03 mar. 2019.

SILVA, Jan Alyne Barbosa e. Weblog: múltiplas utilizações e um conceito. In: CONGRESSO BRASILEIRO DE CIÊNCIAS DA COMUNICAÇÃO, 26., 2003, Belo Horizonte, Minas Gerais. Anais [...] Belo Horizonte: INTERCOM, 2003. Disponível em: http://penta3.ufrgs.br/PEAD/Semana01/2003_NP08_silva.pdf. Acesso em: 03 mar. 2019.

SILVA, Leyde Klebia Rodrigues da; SILVA JÚNIOR, Jobson Francisco da; AQUINO, Mirian de Albuquerque. Gêneros digitais: expandindo a comunicação do Movimento Negro na Paraíba. Revista Digital de Biblioteconomia e Ciência da Informação, Campinas, v. 12, n. 2, p. 242-263, maio/ago. 2014. Disponível em:

https://periodicos.sbu.unicamp.br/ojs/index.php/rdbci/article/view/1613. Acesso em: 03 mar. 2019.

SILVA JÚNIOR, Jobson Francisco da. A construção da identidade negra a partir de informações disseminadas em blogs de funk. 2014. Dissertação (Mestrado em Ciência da 
Informação) - Centro de Ciências Sociais Aplicadas, Universidade Federal da Paraíba, João Pessoa, 2014.

SILVEIRA, Alex da. Dos jornais revolucionários aos blogs: a preservação das manifestações políticas por meio do web archiving. In: CONGRESSO BRASILEIRO DE BIBLIOTECONOMIA, DOCUMENTACÃO E CIÊNCIA DA INFORMAÇÃO, 24., 2011, Maceió. Anais [...] Maceió: Febab, 2011. Disponível em:

http://www.febab.org.br/congressos/index.php/cbbd/xxiv/paper/view/181/449. Acesso em: 03 mar. 2019.

SOUSA, Paulo Jorge et al. A blogosfera: perspectivas e desafios no campo da Ciência da Informação. Cadernos BAD, Lisboa, n. 1, p. 87-106, jan./jun. 2007.

SOUSA, Rodrigo Silva Caxias de; CAREGNATO, Sonia Elisa. A comunicação científica nos blogs de pesquisadores brasileiros: interpretações segundo categorias obtidas da análise de links. Liinc em Revista, Rio de Janeiro, v. 8, n. 2, p. 448-465, set. 2012. Disponível em: http://revista.ibict.br/liinc/article/view/3369/2970. Acesso em: 03 mar. 2019.

TARGINO, Maria das Graças. Blogs como instrumento de legitimação de lutas sociais em Cuba. Informação \& informação, Londrina, v. 18, n. 3, p. 199-221, set./dez. 2013.

Disponível em:

http://www.uel.br/revistas/uel/index.php/informacao/article/view/15134/pdf_11. Acesso em: 03 mar. 2019.

VEGA, José Antonio Merlo; ROJO, Ángela Sorli. Weblogs: um recurso para los profissionales de la información. Revista Española de Documentación Cientifica, v. 26, n. 2, p. 227-236, abr./jun. 2003. Disponível em:

http://redc.revistas.csic.es/index.php/redc/article/view/236/292. Acesso em: 03 mar. 2019.

VIEIRA, David Veron; BAPTISTA, Sofia Galvão. Uma teoria crítica da "biblioteca 2.0" para a situação dos blogs de bibliotecas no Brasil. CONGRESSO BRASILEIRO DE BIBLIOTECONOMIA, DOCUMENTAÇÃO E CIÊNCIA DA INFORMAÇÃO, 24., 2011, Maceió. Anais [...] Maceió: Febab, 2011. Disponível em: http://febab.org.br/congressos/index.php/cbbd/xxiv/paper/view/340/430. Acesso em: 03 mar. 2019. 